MEXAHIKA

MECHANICS

https://doi.org/10.15407/dopovidi2021.03.033

УдК 539.3

Б.М. Стасюк ${ }^{1,2}$, https://orcid.org/0000-0001-9713-191X

1 Інститут прикладних проблем механіки і математики ім. Я.С. Підстригача НАН України, Львів

2 Національний університет “Львівська політехніка”

E-mail: stasyuk.bohdan.m@gmail.com

\title{
Напруження у порожнистому циліндрі, послабленому множинними тріщиноподібними дефектами
}

Представлено академіком НАН Украӥни Р. М. Кушніром

У роботі тривимірний напружений стан порожнстого, безмежного вздовж осі пружного циліндра, що містить множинні внутрішні тонкі податливі включення чисельно моделюється модифікованим методом граничних інтегральних рівнянь. 3 цією метою гіперсингулярні інтеграли на поверхнях включень подаються у формі, в якій поведінка розв’язку поблизу їх контурів враховується неявно. Ця модифікація дозволяє уніфікувати дискретизацію рівнянь методом колокацій, а також безпосередньо визначити коефіцієнти інтенсивності напружень на контурах серединних поверхонь включень. Отримано числові розв'язки задачі взаємодії двох кругових податливих включень, серединна поверхня яких лежить в одній площині з віссю порожнистого циліндра, що перебуває під дією внутрішнього тиску.

Ключові слова: дискові податливі включення, коефічієнти інтенсивності напружень, метод граничних інтегральних рівнянь, метод граничних елементів.

Оцінка міцності та надійності пружних тіл обмежених криволінійними поверхнями, що містять дефекти, є важливим і актуальним завданням, що вирішується для забезпечення надійного функціонування магістральних трубопроводів. За наявності в таких конструкціях множинних тріщиноподібних дефектів необхідно додатково проводити міцністні розрахунки, позаяк останні можуть зумовлювати значні концентрації напружень і призвести за подальшої експлуатації трубопроводу до його передчасного руйнування [1].

В існуючих стандартах розглядаються лише плоскі тріщини кругової та еліптичної форми [2], які розташовані в площині поперечного перерізу труби. Проте, сучасні інтелектуальні поршні під час планового діагностування експлуатованих магістральних трубопроводів здатні досить точно виявляти наявність значно ширшого класу довільно орієнтованих тріщиноподібних дефектів, серед яких значний відсоток складають податливі тонкі включення [3]. Існуючі на сьогодні спрощені розрахункові моделі не здатні повною мірою використати цю

Ц и т у в а н н я: Стасюк Б.М. Напруження у порожнистому циліндрі, послабленому множинними тріщиноподібними дефектами. Допов. Наи. акад. наук Укр. 2021. № 3. С. 33-39. https://doi.org/10.15407/dopovidi 2021.03.033 


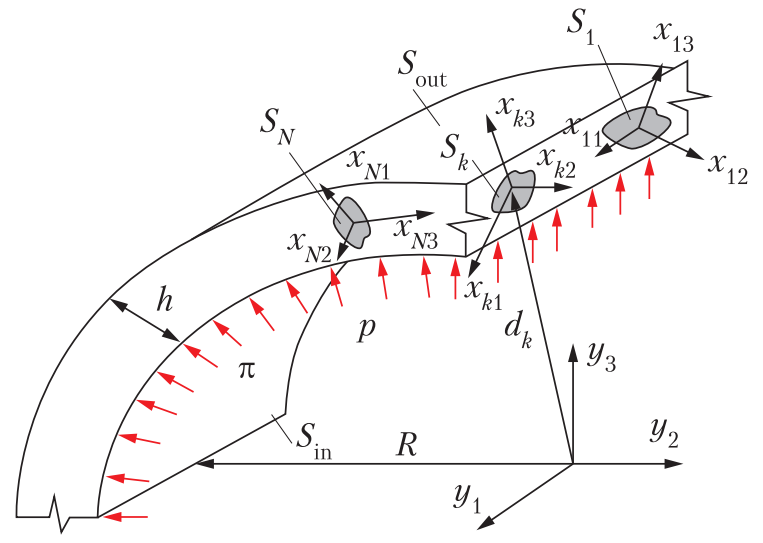

Puc. 1

інформацію для точної оцінки ресурсу ділянок трубопроводів, послаблених множинними дефектами такого типу. Зокрема, до цього часу в літературі переважають розв'язки тривимірних задач механіки руйнування без врахування взаємодії поверхонь тонких включень $з$ поверхнею тіла $[4,5]$ або задач в плоскій чи антиплоскій постановці [6].

Основною метою даного дослідження є модифікація методу граничних інтегральних рівнянь, базованого на теорії потенціалів для отримання оцінки локальної міцності порожнистого циліндра із внутрішніми тонкими пружними включеннями при комбінованому навантаженні, що дозволить оптимізувати $\mathrm{i}$ економічно знизити затрати експлуатації трубопровідної системи. Обмеження на топологію та орієнтацію включень можна зняти застосувавши числові методи обернення систем сингулярних інтегральних рівнянь, серед яких найбільш ефективним можна вважати метод граничних елементів [7].

Постановка задачі. Розглядається безмежний вздовж осі однорідний пружний порожнистий циліндр $\Omega$, обмежений двома циліндричними поверхнями: $S_{\text {out }}$ радіусом $R+h_{0}$ та $S_{\text {in }}$ радіусом $R$. Нехай фрагмент тіла $\Omega$ містить $N$ довільно орієнтованих внутрішніх тонких включень малої жорсткості товщиною $h_{k}$, серединні поверхні яких позначимо через $S_{k}$ $(k=\overline{1, N})$ (рис. 1). Механічні властивості матеріалів визначаються модулями зсуву і коефіцієнтами Пуассона порожнистого циліндра $\left(G_{0}, v_{0}\right)$ та пружних включень $\left(G_{k}, v_{k}, k=\overline{1, N}\right)$. Тіло $\Omega$ знаходиться під дією статичного навантаження його зовнішньої поверхні $S_{\text {оut }}$ в точках, безмежно віддалених від системи взаємодіючих включень та постійного тиску $p$ на внутрішній поверхні $S_{\text {in }}$. Поверхні включень вільні від навантажень.

Виділимо напружено-деформований стан в тілі, викликаний стрибком переміщень на поверхнях $k$-го включення, $u_{i}^{(k)} ; \sigma_{i j}^{(k)}(i, j=\overline{1,3})$, описуючи його в системі координат $O_{k} x_{k 1} x_{k 2} x_{k 3}$, що прив'язана до центра цього включення. Вісь $O_{k} x_{k 3}$ завжди будемо спрямовувати в напрямку, перпендикулярному до області $S_{k}$ так, що поверхні включення можна описати залежністю $x_{k 3}= \pm h_{k}\left(x_{k 1}, x_{k 2}\right)$. Тут і надалі характеристики напружено-деформованого стану будемо позначати верхніми індексами, що означатиме причину їх появи. Величини $u_{i}^{(0)} ; \sigma_{i j}^{(0)}(i, j=\overline{1,3})$, що визначатимуть напружено-деформований стан в бездефектному тілі $\Omega$ з аналогічними пружними характеристиками під дією заданого навантаження, задаємо в системі координат $O y_{1} y_{2} y_{3}$, початок якої знаходиться в центрі поперечного перерізу порожнистого циліндра.

Положення включень опишемо $з$ допомогою радіус-вектора $\overrightarrow{\mathbf{d}}_{k}$ центра $k$-го включення та його напрямних косинусів $e_{k j}(j=\overline{1,3})$ у глобальній системі координат $O y_{1} y_{2} y_{3}$. Положення центра глобальної системи координат відносно $k$-го включення задамо протилежним вектором $\overrightarrow{\mathbf{d}}_{k}^{*}$ та його напрямними косинусами $e_{k j}^{*}$ в системі координат $O_{k} x_{k 1} x_{k 2} x_{k 3}$. Через $l_{i j k}=\cos \left(O_{k} x_{k i}, O y_{j}\right) \quad(i, j=\overline{1,3})$ позначимо косинуси кутів між осями локальних $\mathrm{i}$ глобальної систем координат. 
Розв’язування задачі методом ГІР. Принцип суперпозиції дозволяє визначити загальний напружено-деформований стан в тілі як суму напружених станів, описаних вище:

$$
\sigma_{i j}(\mathbf{x})=\sum_{k=0}^{N} \sigma_{i j}^{(k)}(\mathbf{x}), \quad u_{i}(\mathbf{x})=\sum_{k=0}^{N} u_{i}^{(k)}(\mathbf{x}), \quad i, j=\overline{1,3} .
$$

Для перетворення компонент тензора напружень і вектора переміщень в різних системах координат слід використовувати формули:

$$
u_{i}^{(k)}(\mathbf{x})=\sum_{m=1}^{3} u_{m}(\mathbf{y}) l_{i m k} ; \quad \sigma_{i j}^{(k)}(\mathbf{x})=\sum_{l=1}^{3} \sum_{m=1}^{3} \sigma_{l m}(\mathbf{y}) l_{i l k} l_{j m k}, \quad j=\overline{1,3} .
$$

Крайові умови на поверхнях порожнистого циліндра в глобальній системі координат $O y_{1} y_{2} y_{3}$ мають вигляд $(j=\overline{1,3})$ :

$$
\left.u_{j}(\mathbf{y})\right|_{\mathbf{y} \in S_{\text {in }} \cup S_{\text {out }}}=u_{j}^{*}(\mathbf{y}),\left.\quad \sigma_{3 j}(\mathbf{y})\right|_{\mathbf{y} \in S_{\text {in }}}=-p n_{j},\left.\sigma_{3 j}(\mathbf{y})\right|_{\mathbf{y} \in S_{\text {out }}}=0 .
$$

Крайові умови на поверхнях включень в системі координат $O_{k} x_{k 1} x_{k 2} x_{k 3}$ представимо у вигляді залежностей [4]:

$$
\left.\sigma_{3 j}^{(k)}(\mathbf{x})\right|_{\mathbf{x} \in S_{k}}=4 \pi G_{k}\left(\frac{2+2 v_{k}}{1-2 v_{k}}\right)^{\delta_{j 3}} \frac{\alpha_{k j}(\mathbf{x})}{h_{k}(\mathbf{x})}, \quad \mathbf{x} \in S_{k}, \quad j=\overline{1,3},
$$

де $\delta_{j 3}-$ символ Кронекера.

Використовуючи інтегральні подання Сомільяно компонент вектора переміщень та тензора напружень в тілі, викликаних деформацією порожнистого циліндра [7] і деформаціями включень [8] та здійснюючи граничний перехід в (1) до точок поверхонь порожнистого циліндра і серединних поверхонь включень з урахуванням граничних властивостей потенціалів простого і подвійного шару [11], а також задовольняючи крайові умови (2), (3), отримаємо:

$$
\begin{aligned}
& \frac{1}{2} u_{i}^{*}(\mathbf{y})-\sum_{j=1}^{3} \iint_{S_{i n} \cup S_{\text {out }}} T_{i j}(\mathbf{y}, \xi) u_{j}^{*}(\xi) d S-\sum_{k=1}^{N} \sum_{j=1}^{3} \iint_{S_{k}} \Phi_{i j}\left(\tilde{\mathbf{y}}^{(k)}, \xi\right) l_{i j k} \alpha_{k j}(\xi) d_{\xi} S= \\
& =u_{i}^{(0)}(\mathbf{y})+\sum_{j=1}^{3} \iint_{S_{\text {in }}} U_{i j}(\mathbf{y}, \xi) p n_{j}(\xi) d S_{\xi}, \mathbf{y}, \tilde{\mathbf{y}}^{(k)} \in S_{\text {in }}, S_{\text {out }} ; i=\overline{1,3}, \\
& -4 \pi \frac{G_{k}}{G_{0}}\left(1-v_{0}\right)\left(\frac{2+2 v_{k}}{1-2 v_{k}}\right)^{\delta_{j 3}} \frac{\alpha_{k i}(\mathbf{x})}{h_{k}(\mathbf{x})}+\sum_{m=1}^{3} \iint_{S_{k}} K_{i 3 m}(\mathbf{x}, \xi) \alpha_{k m}(\xi) d S_{\xi}+ \\
& +\frac{1-v_{0}}{G_{0}} \sum_{s=1}^{3} \sum_{j=1}^{3} \sum_{m=1}^{3} \iint_{S_{i n} \cup S_{\text {out }}} L_{s j m}\left(\hat{\mathbf{x}}^{(k)}, \xi\right) l_{3 s k} l_{j i k} u_{m}^{*}(\xi) d S_{\xi}=\frac{1-v_{0}}{G_{0}} \sum_{j=1}^{3} \sum_{m=1}^{3} \sigma_{j m}^{(0)}(\mathbf{x}) l_{3 m k} l_{j i k}- \\
& -p \frac{1-v_{0}}{G_{0}} \sum_{s=1}^{3} \sum_{j=1}^{3} \sum_{m=1}^{3} \iint_{S_{i n}} D_{s j m}\left(\hat{\mathbf{x}}^{(k)}, \xi\right) l_{3 s k} l_{j i k} n_{m}(\xi) d S_{\xi}, \mathbf{x}, \hat{\mathbf{x}}^{(k)} \in S_{k} ; i=\overline{1,3 ; k=1, N},
\end{aligned}
$$




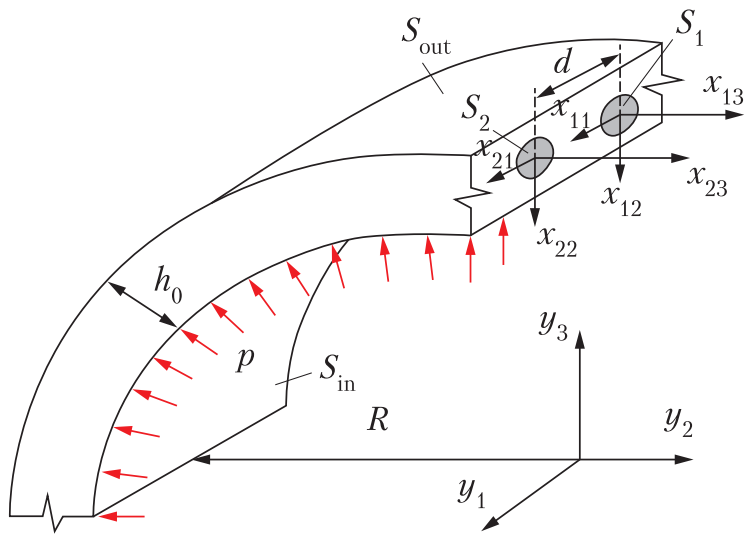

Puc. 2

де $u_{j}^{*}$ - значення компонент вектора переміщень в точках поверхонь $S_{\text {in }}, S_{\text {out }}$ з боку вектора нормалі $\mathbf{n}$; функції $\alpha_{k j}(\xi)=\left(u_{k j}^{-}(\xi)-\right.$ $\left.-u_{k j}^{+}(\xi)\right) /\left.4 \pi\right|_{\xi \in S_{k}},(j=\overline{1,3}) є$ нормованими стрибками точок поверхонь $k$-го включення в напрямку осей $\mathrm{O}_{k} x_{k j} ; U_{i j}, T_{i j}, D_{i j m}, S_{i j m}$ [7], $\Phi_{i j}, K_{i j m}[8]-$ відомі ядра типу ньютонівського потенціалу, що залежать від механічних характеристик матеріалу порожнистого циліндра; символами “ $(k)$ ” позначаємо координати точки, яка належить поверхні порожнистого циліндра, записані в локальній системі координат, що прив'язана до $k$-го включення; символи “^ $(k)$ ” означають координати точки, яка лежить на серединній поверхні $k$-го включення, записані в глобальній системі координат. При цьому перетворення координат при переході від однієї системи координат до іншої є такі:

$$
\tilde{y}_{i}^{(k)}=e_{k i} d_{k}+\sum_{s=1}^{3} l_{s i k} y_{s}, \quad \hat{x}_{i}^{(k)}=e_{k i}^{*} d_{k}^{*}+\sum_{s=1}^{2} l_{i s k} x_{s}^{(k)}, \quad i=\overline{1,3} .
$$

3 метою дискретизації рівнянь (4) апроксимуємо поверхні $S_{i n}, S_{\text {out }}$ та $S_{k}(k=\overline{1, N})$ неперервною сукупністю криволінійних граничних елементів. Зауважимо, що довжину фрагмента порожнистого циліндра, поверхні якого потрібно замінити сіткою граничних елементів вибираємо виходячи з відстані до розглядуваної системи включень. Вплив деформації включень на переміщення вузлів крайніх граничних елементів повинен бути нехтувано малим. Обчислення показують, що відстань від крайнього граничного елемента до найближчого включення повинна перевищувати 5 характерних діаметрів включень. Особливості регуляризації сингулярних та гіперсингулярних інтегралів, а також побудови дискретного аналогу системи інтегральних рівнянь (4) подано в роботах [9, 10].

Результатом розв’язування дискретного аналогу системи ГІР (4) є визначення значень компонентів вектора переміщень в кутових вузлах граничних елементів поверхонь порожнистого циліндра $S_{\text {in }}$ та $S_{\text {out }}$ і значень функцій стрибків переміщень у вузлах граничних елементів поверхонь $S_{k}(k=\overline{1, N})$.

У випадку розташування дископодібних кругових включень у площині, що проходить через вісь порожнистого циліндра, навантаженого лише внутрішнім тиском, внаслідок симетрії задачі, відмінний від нуля коефіцієнт інтенсивності напружень (КIH) на контурі серединної поверхні $k$-го включення з радіусом $a_{k}$ обчислюємо через стрибок переміщень його поверхонь за формулами [4]:

$$
K_{1}^{(k)}\left(x_{k 0}\right)=-2 \pi \sqrt{a_{k} \pi} \frac{G_{0}}{1-v_{0}} \beta_{k 3}\left(x_{k 0}\right),
$$

де $\beta_{k 3}(\mathbf{x})=\alpha_{k 3}(\mathbf{x}) / \sqrt{a_{k}^{2}-x_{k 1}^{2}-x_{k 2}^{2}}-$ модифікована функція стрибків переміщень поверхонь $k$-го включення; $x_{k 0}-$ точка контуру поверхні $S_{k} k$-го включення. 


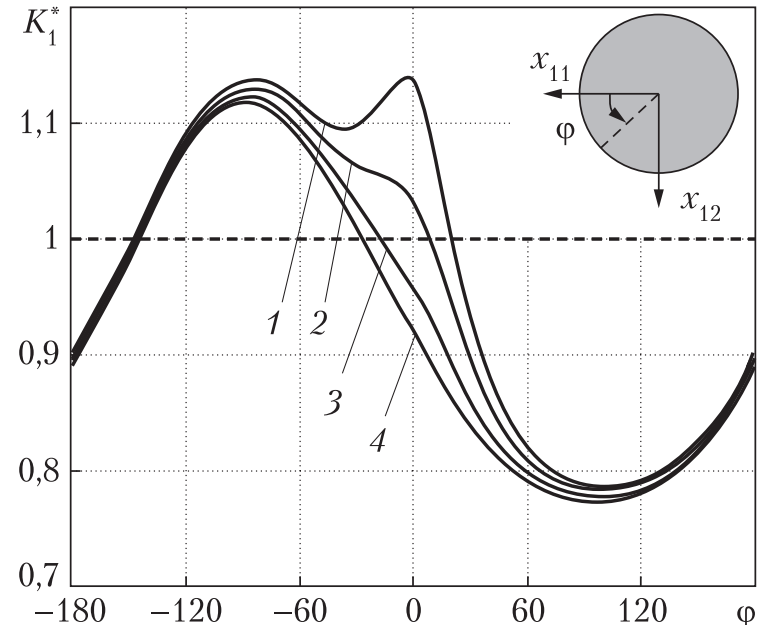

Puc. 3

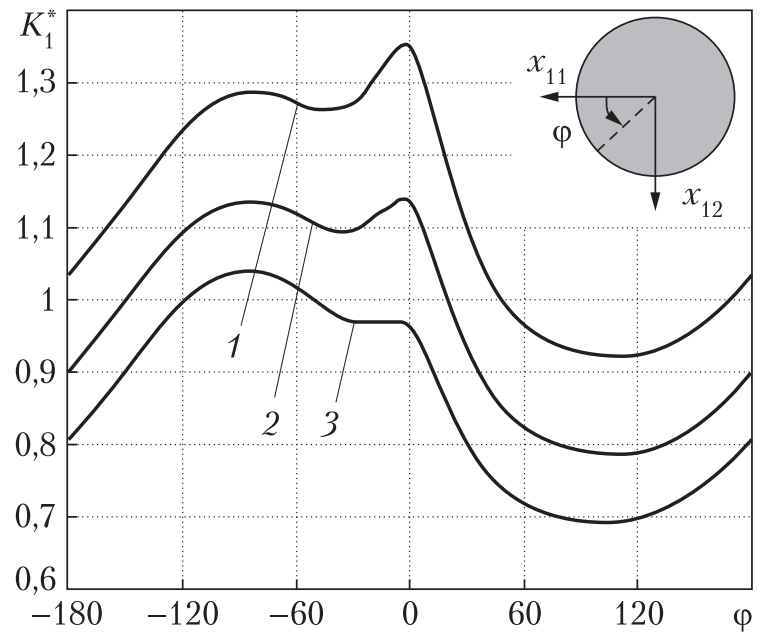

Puc. 4

Аналіз одержаних результатів. Як приклад, розв'язано задачу взаємодії двох дископодібних кругових включень з радіусом $a=0,3 h_{0}$ та товщиною $h_{1}=h_{2}=0,01 a$, серединна поверхня яких лежить в одній площині з віссю порожнистого циліндра (рис. 2). Відстань центрів включень до поверхні $S_{\text {in }}$ позначимо через $b$. На поверхні $S_{\text {in }}$ діє постійний внутрішній тиск $p$. Коефіцієнти Пуассона матеріалу порожнистого циліндра та включень приймаємо рівними між собою $v_{0}=v_{1}=v_{2}=0,3$. Зважаючи на однакову глибину залягання включень отримаємо симетричну задачу, що дозволяє аналізувати розподіл КІН лише для одного включення. Розташування включень визначаються величинами $e_{k 1}=-e_{k 1}^{*}=(-1)^{k+1} d / \sqrt{4(R+b)^{2}+d^{2}}$; $e_{k 2}=e_{k 3}^{*}=0 ; e_{k 3}=e_{k 2}^{*}=(R+b) / \sqrt{(R+b)^{2}+(d / 2)^{2}} ;(k=1,2)$, а їх орієнтація відносно глобальної системи координат - напрямними косинусами $l_{11 k}=-l_{23 k}=l_{32 k}=1 ; l_{12 k}=l_{13 k}=$ $l_{21 k}=l_{22 k}=l_{31 k}=l_{33 k}=0$.

На рис. 3 та 4 показані залежності приведеного значення КІН $K_{1}^{*}=K_{1} / \hat{k}_{1}$ від кутової координати $\varphi$ контуру серединної поверхні $S_{1}$ включення за фіксованої глибини залягання взаємодіючих включень $\left(b=h_{0} / 2\right)$, де $\hat{k}_{1}=2 \sigma_{\theta} \sqrt{a / \pi}-$ КІН для ізольованої кругової тріщини такого ж розміру, що перебуває в безмежному тілі під дією навантаження:

$$
\sigma_{\theta}=\frac{R^{2} p}{h_{0}^{2}+2 R h_{0}}\left(1+\frac{\left(R+h_{0}\right)^{2}}{(R+b)^{2}}\right) .
$$

На рис. 3 цифрами позначені криві, що відповідають різній відстані між центрами включень за фіксованої їх податливості $\left(G_{1} / G_{0}=G_{2} / G_{0}=0,001\right): 1-d / a=2,1 ; 2-d / a=2,2$; $3-d / a=2,4 ; 4-d / a=2,7$. Штриховою лінією позначено КІН для аналогічної кругової тріщини в безмежному просторі (без врахування взаємодії з поверхнями циліндра). На рис. 4 цифрами позначені криві, що відповідають різній податливості включень за фіксованої відстані між ними $(d / a=2,1): 1-G_{1} / G_{0}=G_{2} / G_{0}=0$ (випадок взаємодіючих в порожнистому циліндрі тріщин); $2-G_{1} / G_{0}=G_{2} / G_{0}=0,001 ; 3-G_{1} / G_{0}=G_{2} / G_{0}=0,005$.

Висновки. Числовий експеримент зміни густини сітки граничних елементів показує, що точність запропонованого методу забезпечується в межах 2 \% при використанні 144 ко- 
локаційних вузлів на серединній поверхні кожного включення та 240 суперпараметричних граничних елементів на поверхнях порожнистого циліндра. Отримані запропонованим методом результати достатньо добре корелюють з відомими в літературі частковими випадками даної задачі, зокрема була протестована задача взаємодії двох податливих включень у просторі [4].

Як видно з отриманих результатів, внутрішній тиск у порожнистому циліндрі спричинює меншу концентрацію напружень в точках включень, наближених до внутрішньої поверхні порівняно з впливом зовнішньої поверхні тіла. Пікові значення КІН в точці контуру серединної поверхні включення, що наближена до сусіднього включення, виникають лише за умови дуже близького їх розташування $(d / a \leqslant 2,1)$. При збільшенні жорсткості та незмінному розташуванні взаємодіючих включень КІН на всьому їх контурі нерівномірно зменшується: в точках, наближених до сусіднього включення, більше ніж в точках, наближених до поверхонь тіла. Збільшення кривизни зовнішньої поверхні $S_{\text {оиt }}$ зумовлює збільшення максимального значення КІН.

\section{ЦИТОВАНА ЛІТЕРАТУРА}

1. Kryzhanivs'kyi E.I., Hrabovs'kyi R.S., Mandryk O.M. Estimation of the serviceability of oil and gas pipelines after long-term operation according to the parameters of their defectiveness. Materials Science. 2013. 49, №1. P. 117-123. https://doi.org/10.1007/s11003-013-9590-6

2. Державний стандарт України: ДСТУ Н Б В.2.3-21:2008. Визначення залишкової міцності магістральних трубопроводів з дефектами: нормативно-технічний матеріал. Київ: Мінрегіонбуд України, 2008. 64 с.

3. Державний стандарт України: ДСТУ EN ISO 16826:2015 Неруйнівний контроль. Ультразвуковий контроль. Виявлення несуцільностей перпендикулярних до поверхні. Київ: ДП «УкрНДНЦ», 2015. 73 с.

4. Бутрак I. Вплив гармонічної хвилі на концентрацію напружень у безмежному тілі з податливими дисковими включеннями. Фізико-математичне моделювання та інформаційні технології. 2015. 21. С. 30-38.

5. Панасюк В. В., Стадник М. М., Силованюк В. П. Концентрация напряжений в трехмерных телах с тонкими включениями. Київ: Наук. думка, 1986. 216с.

6. Kyrylova, O.I., Mykhas'kiv, V.V. Harmonic Vibration and Resonance Effects in the Case of Longitudinal Shear of a Hollow Cylinder with Crack. Materials Science. 2019. 55, №1. P. 114-123. https://doi.org/10.1007/ s11003-019-00258-3

7. Balas J., Sladek J., Sladek V. Stress Analysis by Boundary Element Methods. Amsterdam: Elsevier, 1989. 686 c.

8. Stasyuk B. M. Influence of a gas-filled cavity of complex shape on stresses in the vicinity of a neighboring crack. Materials Science. 2014. 49, № 6. P. 734-742. https://doi.org/10.1007/s11003-014-9668-9

9. Михаськив В.В., Стасюк Б.М. О численном решении трехмерных статических задач теории упругости для тел с включением неканонической формы. Прикл. механика. 2007. 43, № 4. С. 27-35.

10. Mykhas'kiv V.V., Stasyuk B.M. Stress intensification due to the crack outside/inside a finite fiber in 3-D elastic matrix. Theor. Appl. Fract. Mech. 2015. 80. P 133-142. https://doi.org/10.1016/j.tafmec.2015.10.002

Надійшло до редакції 06.04.2021

\section{REFERENCES}

1. Kryzhanivs'kyi, E. I., Hrabovs'kyi, R. S. \& Mandryk, O. M. (2013). Estimation of the serviceability of oil and gas pipelines after long-term operation according to the parameters of their defectiveness. Materials Science. 49, No. 1, pp. 117-123. https://doi.org/10.1007/s11003-013-9590-6

2. State Standard of Ukraine: DSTU N B V.2.3-21: 2008. (2008). Determination of residual strength of main pipelines with defects: regulatory and technical material. Kyiv: Minrehionbud Ukraine. 64 p. (in Ukrainian).

3. State standard of Ukraine: DSTU EN ISO 16826:2015 (2015). Non-destructive testing. Ultrasonic control. Examination for discontinuities perpendicular to the surface. Kyiv: DP «UkrNDNC». 73 p. (in Ukrainian). 
4. Butrak, I. (2015). The influence of harmonic wave on the concentrationof stresses in the infinite solid with pliable disk-shaped inclusions. Fizyko-matematychne modeliuvannia ta informatsiini tekhnolohii. 21, pp. 30-38 (in Ukrainian).

5. Panasiuk, V. V., Stadnyk, M. M. \& Sylovaniuk, V. P. (1986). Stress concentration in three-dimensional bodies with thin inclusions. Kyiv: Naukova Dumka. (in Ukrainian).

6. Kyrylova, O. I. \& Mykhas'kiv, V. V. (2019). Harmonic Vibration and Resonance Effects in the Case of Longitudinal Shear of a Hollow Cylinder with Crack. Materials Science. 55, №1, pp. 114-123. https://doi. org/10.1007/s11003-019-00258-3

7. Balas, J., Sladek, J. \& Sladek, V. (1989). Stress Analysis by Boundary Element Methods. Amsterdam: Elsevier. $686 \mathrm{p}$.

8. Stasyuk, B. M. (2014). Influence of a gas-filled cavity of complex shape on stresses in the vicinity of a neighboring crack. Materials Science. 49, No. 6, pp. 734-742. https://doi.org/10.1007/s11003-014-9668-9

9. Mykhas'kiv, V. V. \& Stasyuk, B. M. (2007). Numerical solution of three-dimensional static problems of elasticity for a body with a noncanonical inclusion. International Applied Mechanics. 43, No. 4, pp. 380-387. https://doi.org/10.1007/s10778-007-0033-7

10. Mykhas'kiv, V. V. \& Stasyuk, B. M. (2015). Stress intensification due to the crack outside/inside a finite fiber in 3-D elastic matrix. Theor. Appl. Fract. Mech. 80, pp 133-142. https://doi.org/10.1016/j.tafmec. 2015.10 .002

Received 06.04.2021

B.M. Stasyuk ${ }^{1,2}$, https://orcid.org/0000-0001-9713-191X

${ }^{1}$ Pidstryhach Institute for Applied Problems of Mechanics and Mathematics of the NAS of Ukraine, Lviv

2 Lviv Polytechnic National University

Email: stasyuk.bohdan.m@gmail.com

\section{STRESS IN A HOLLOW CYLINDER WEAKENED BY MULTIPLE CRACK-LIKE DEFECTS}

The three-dimensional stressed state of an elastic hollow cylinder, boundless along the axis containing multiple internal thin pliable inclusions is numerically modeled by a modified method of boundary integral equations. For this purpose, hypersingular integrals on the inclusion's surfaces are presented in the form in which the behavior of the solution near their contours is implicitly taken into account. This modification allows us to unify the discretization of equations by the method of collocations and to directly determine the stress intensity factors on the contours of the inclusion's midsurfaces. Numerical solutions of the problem of the interaction of two circular pliable inclusions are obtained. The irmidsurface lies in the same plane with the axis of the hollow cylinder, which is under the action of internal pressure.

Keywords: disk pliable inclusions, stress intensity factor, boundary integral equations method, method of boundary elements. 